\title{
Creating action plans in a serious video game increases and maintains child fruit-vegetable intake: a randomized controlled trial
}

Debbe Thompson ${ }^{1 *}$, Riddhi Bhatt ${ }^{2}$, Isabel Vazquez ${ }^{1}$, Karen W Cullen ${ }^{1}$, Janice Baranowski ${ }^{1}$, Tom Baranowski ${ }^{1}$ and Yan Liu'

\begin{abstract}
Background: Child fruit and vegetable intake is below recommended levels, increasing risk for chronic disease. Interventions to influence fruit and vegetable intake among youth have had mixed effects. Innovative, theory-driven interventions are needed. Goal setting, enhanced by implementation intentions (i.e., plans tightly connected to a behavioral goal), may offer a solution. Action plans state "how" a goal will be achieved, while coping plans identify a potential barrier and corresponding solution. The research reported here evaluated the short- and long-term effects of goal setting enhanced with implementation intentions on child fruit and vegetable intake in a 10-episode, theoretically-grounded serious videogame promoting fruit and vegetables. This is one of the first studies to test the efficacy of implementation intentions on the dietary intake of healthy children.

Methods: A four-group randomized design with three data collection periods (baseline, immediate post-intervention, 3 months post-intervention) was employed. Groups varied on whether children created an implementation intention (none, action, coping, both) as part of goal setting. Participants were 4th and 5th grade children ( 9-11 years old) and one parent. An a priori power analysis indicated this would provide $>80 \%$ power to detect a small effect (Cohen's $d=0.17$ ). Children played a 10-episode online videogame; parents received 10 electronic newsletters and access to a parent-only website. The primary outcome was child fruit and vegetable intake, assessed via three, dietitian-assisted telephone recalls at each data collection period. The primary analysis was conducted using a repeated measures analysis of covariance with a mixed model procedure. Secondary analyses examined intervention effects on fruit and vegetables separately.
\end{abstract}

Results: Four hundred parent/child dyads were recruited. A significant group-by-time interaction for fruit and vegetable intake ( $p<0.001)$ was found in only the Action group, which had significant increases in fruit and vegetable intake at post $1(p<0.0001)$ and post $2(p<0.0001)$. No other significant interactions were observed; however, there were significant time effects for fruit $(p<0.0001)$.

Conclusions: Action intentions may be an important component of successful interventions to increase and maintain fruit and vegetable intake in pre-adolescent children. Videogames promoting healthy diets offer an effective vehicle for delivering behavior change interventions to children.

Trial registration: ClinicalTrials.gov NCT01004094.

Keywords: Videogame, Fruit, Vegetables, Children, Implementation intentions, Maintenance

\footnotetext{
* Correspondence: dit@bcm.edu

'USDA/ARS Children's Nutrition Research Center, Baylor College of Medicine,

1100 Bates Street, Houston, TX, USA

Full list of author information is available at the end of the article
}

\section{Biomed Central}

(c) 2015 Thompson et al.; licensee BioMed Central. This is an Open Access article distributed under the terms of the Creative Commons Attribution License (http://creativecommons.org/licenses/by/4.0), which permits unrestricted use, distribution, and reproduction in any medium, provided the original work is properly credited. The Creative Commons Public Domain Dedication waiver (http://creativecommons.org/publicdomain/zero/1.0/) applies to the data made available in this article, unless otherwise stated. 


\section{Background}

Fruit and vegetable (FV) intake is part of a healthy lifestyle [1] and reduces risk of developing chronic diseases, such as cardiovascular disease, hypertension, and certain cancers $[2,3]$. Due to their low energy density, FV intake may also decrease total calorie intake [4], thus reducing risk of obesity in the adult years [5]. FV intake behaviors are established early in life [6], and tend to track into adulthood [7-9], thus increasing the importance of establishing these behaviors during childhood.

National recommendations for pre-adolescent children encourage consuming 7-11 servings of FV per day[10]. Using MyPyramid as a guide, this equates to daily minimums of 1.5 cup equivalents of fruit (F) and $2.0-2.5$ of vegetables (V) [11]. However, few children met even the minimum recommendation [11]. Interventions to increase FV intake among children have had mixed effects $[12,13]$; thus, new and effective intervention approaches are needed.

Theory provides a framework for developing interventions focused on factors that influence a specific behaviour, such as FV intake [14]. Goal setting, a theorydriven technique [15], is a promising dietary behaviour change procedure $[16,17]$. Although goal setting is often included in dietary behaviour change interventions for children [18-24], few studies have tested the effect of goal setting on dietary intake or investigated ways to enhance its effectiveness with children [25-28]. Because child preferences for FV vary [29], interventions to increase child FV intake should be responsive to this by enabling children to meet their goals by choosing preferred FV.

Implementation intentions are detailed plans tightly connected to a specific goal [30,31]. Expanding goal setting to include implementation intentions may enhance goal attainment [30-32] and thus, intervention effectiveness. There are two types of implementation intentions: action plans and coping plans. Action plans are highly specified plans that describe how (i.e., what, when, where) the goal will be attained (i.e., an action plan). Youth encounter barriers when attempting to eat FV [33], and problem solving is a common method for developing a plan to overcome them [34,35]. Coping plans, a type of problem solving, are designed to help children overcome common barriers or problems that may interfere with $\mathrm{FV}$ consumption $[21,36]$. Coping plans take an "if/then" approach, and guide the child through a process that identifies a specific barrier that may occur to hinder goal attainment and a course of action that will be taken if the barrier is encountered [30,37]. Implementation intentions have been effective at enhancing a variety of goal-directed behaviors, particularly among adults [31]. However, there is little evidence of effectiveness with healthy children, particularly in regards to diet $[31,38,39]$. More research is needed to investigate this promising technique.
Interventions to increase FV intake among children are often delivered in-person [12]; however, alternative approaches may be needed to effectively promote increased FV intake in large numbers of children. Videogames may offer an alternative. Children enjoy videogames; play a wide variety of videogame genres; play them often; and live in homes with high speed internet access [40]. Although excessive time spent in entertainment-oriented videogames has been associated with negative health effects [41], serious videogames, an emerging genre, offer a promising intervention approach with children $[18,42,43]$. Serious videogames attempt to change behaviour by integrating theory-driven behaviour change techniques (e.g., goal setting, problem solving) into a fun and engaging videogame $[36,42,44]$ i.e., they attempt to integrate the "serious" aspects of behaviour change with the "fun" aspects of an entertainment-oriented videogame. Advantages of delivering behavior change interventions in a videogame format include high fidelity to intervention design and content; consistent delivery (i.e., delivered in the same way to every participant); and familiarity. Thus, promoting FV intake to children using a serious videogame delivered over the internet would be convenient, familiar, and delivered with high fidelity. This paper presents the outcome evaluation of an online serious videogame promoting FV to children that systematically varied action and coping implementation intentions and examined the short and longer term effects on FV intake.

\section{Methods}

\section{Study design}

The methods have been described in detail elsewhere, but are briefly summarized here [37]. The outcome evaluation used a four group, randomized design with three data collection periods: baseline, post 1 (immediately post-intervention, which was approximately 3 months after baseline), and post 2 (approximately 3 months postintervention). The child was randomized to condition after both parent and child completed baseline data collection using a random numbers table generated by the study biostatistician.

All groups played the 10-episode online videogame. The groups varied only on type of implementation intention created (Action, Coping, Both, none) after setting a goal to eat FV. Goals were tailored to child's FV preferences and increased in difficulty to enhance the likelihood of goal attainment [37]. The "Action" group set a FV goal and then created an action plan (i.e., implementation intention) specifying how (i.e., who, what, when) they would meet the goal. They did this by sequentially selecting from a menu of pre-determined categories and choices developed in partnership with children (e.g., "Ask Mom to buy the fruit I need, and put 
my challenge sheet on my bathroom mirror when I finish playing Squire's Quest!). Children assigned to the "Coping" group set a goal to eat more FV; they then created a coping plan (i.e., implementation intention) that identified a potential barrier that might keep them from meeting their goal; they did this by selecting from a menu of potential barriers adapted from a previous study with children [36]. They then selected a solution they would try if that barrier was encountered from a menu of barrier-specific solutions (e.g., "If fruit is not always available at home, go grocery shopping with parent/guardian and get the fruit I chose"). Children assigned to the "Both" group set a goal to eat FV, then created both action and coping plans by first creating an action plan, followed by the selection of a barrier and solution using the procedures described above. Children assigned to the "Control "group played the game, but only set a goal to eat FV i.e., they did not create an action or coping implementation intention. As part of goal review which occurred at the beginning of episodes 2-10, children in the Action, Coping, and Both groups reported whether they used the implementation intention they created to meet their FV goal. Episodes were designed to take no more than one hour to complete. Children were asked to attain their FV goal prior to playing the next episode.

\section{Sample}

Inclusionary criteria were: a child in the 4th or 5th grade ( 9-11 year olds) who spoke English, had a computer and high speed Internet access, and a parent willing to participate. The primary outcome was child FV intake. An a priori power analysis indicated a sample of 400 parent/child pairs would provide $>80 \%$ power at an alpha $\leq 0.05$ to detect a small effect size (Cohen's $d=$ 0.17 ), allowing for a $30 \%$ attrition rate. This effect size translates to detecting a group difference of $0.51 \mathrm{FV}$ servings or more. Recruitment methods included posting flyers in community locations likely to be frequented by parents and children, placing notices in electronic newsletters and on websites, and calling eligible families in the USDA/ARS Children's Nutrition Research Center volunteer database. Written parental consent and child assent were obtained prior to participation. Human Subject approval was obtained from the Institutional Review Board at Baylor College of Medicine, Houston, TX, USA (H-18488). The trial was registered with Clinicaltrials. gov (NCT01094004).

\section{Child intervention (videogame) Squire's Quest! II}

Saving the Kingdom of Fivealot (SQ2) is a 10-episode, online videogame designed to encourage 9-11 year old children to consume at least 5 servings of FV each day.
Examples of serving sizes taught in the videogame were $1 / 2$ cup sliced or chopped FV or 1 cup leafy greens. SQ2 is an update and enhancement of the original videogame (Squire's Quest!) (SQ!) played on computers in a classroom setting by 4th grade children [18]. The SQ2 design framework included multiple theories to guide various aspects of behavior change: Social Cognitive Theory for personal and environmental factors that influence FV intake [15]; Self Determination Theory for motivation to eat more FV [45]; Behavioral Inoculation Theory for resistance to temptations not to eat FV [46]; Maintenance Theory for long-term behaviour change (i.e., continued FV intake) [47]; and the Elaboration Likelihood Model for enhanced information processing (e.g., attracting and maintaining attention) [48]. The design framework [37] guided both the behavioural and entertainment-oriented components of the game, including behavioural procedures [15,45-47]; content [15]; character looks [48], personalities [48], and actions [15,49]; storyline [48], and dialogue $[15,45,48,49]$. For a more detailed description, see Thompson et al. [37].

After both parent and child completed baseline data collection, the child became a Squire (i.e., a Knight in training) in the Kingdom of Fivealot. The Squire's mission was to learn the sacred knowledge and skills (e.g., behavioural components designed to increase FV intake) needed to become a Knight to help King Brockwell and Queen Nutritia save the Kingdom from invaders (i.e., snakes and moles) attempting to overthrow the Kingdom by destroying its bountiful FV crops. Squires (players) were assisted in their effort by a "Knight in training" toolkit (e.g., measuring cups and spoons, an apron with the study logo) shipped to them prior to initiating gameplay) and the behavioral components led by game protagonists (i.e., characters). Behavior change components included FV knowledge enhancement (e.g., serving sizes, "real" FV vs FV "imposters", kitchen safety); development of key skills needed to increase and maintain FV intake (e.g., goal setting, problem solving, decision making, self-monitoring, resisting temptation, recipe preparation, asking/negotiation), and demonstrations of how to use strategies (e.g., patterns or schemas) to eat at least 5 servings of FV each day (e.g., the Queen's schema was $1 \mathrm{FV}$ at breakfast, 2 at lunch, 1 at dinner, 1 at snack) [37]. The story, written by a professional writer, was designed to be relevant [48], entertaining [42], and immersive to children [50,51]. It integrated the behaviour change components into the story in a manner that helped advance game-play. The game characters (i.e., protagonists) served as role models [37] who led the knowledge enhancement components of the game, modelled how to perform key skills and behaviors using a coping style [49], and provided performance feedback to the player [15]. 
Extensive formative research was conducted during development to ensure SQ2 was developmentally appropriate and appealing to children. Alpha and beta testing identified technical issues prior to the outcome evaluation. A pilot study was conducted to test procedures (enrollment, data collection, intervention delivery) and serve as a final beta test of the online game. During development, a 4th grade teacher reviewed intervention components to ensure age appropriateness and provided feedback on needed changes to ensure comprehension and appeal.

\section{Parent intervention (electronic newsletters, parent-only website)}

Parents received 10 electronic newsletters and access to a 10-installment parent-only website. The parent intervention was connected to the child intervention. When the child was given access to the next episode of the video game, parents received access to the next installment of the parent intervention. The newsletters informed parents about lesson content for each episode of the videogame and provided a vocabulary list of words in the corresponding episode that might be unfamiliar to the child (e.g., "tome" for book), tips for how they could help their child meet FV goals (e.g., have their favorite FV available), and suggestions for how to overcome barriers families commonly encounter when attempting to eat more FV (e.g., barrier: family does not have time for breakfast; tip: Mix a serving of dry cereal with a serving of raisins or other dried fruit and place in a plastic bag to eat on-the-go). The parent website provided information on ways to create a healthy home environment (e.g., grocery shopping tips, guidelines for creating a wellstocked kitchen to make it easier to prepare quick, healthy, and affordable meals). The parent intervention did not vary by group; all parents received the same intervention, regardless of child group assignment.

\section{Procedures}

After baseline data were collected and children were randomly assigned to group, child and parent were each given a unique password that routed them to their assigned intervention. When parents and children were eligible for the next session, separate emails with links to their intervention were automatically generated and emailed to them simultaneously. Alerts notified the intervention staff when a component was completed by parents and children. Children set two types of goals each episode: a goal to eat more $\mathrm{F}$ and/or $\mathrm{V}$ (i.e., FV goal) and to make a child-friendly FV recipe demonstrated in the game (i.e., FV recipe goal). Episodes varied by whether they promoted F, V, or FV. FV goals were connected to the focus of each episode and were distributed as follows: 3 F, 3 V, 1 F or V, and 3 FV goals. FV goals gradually increased in difficulty and excluded $100 \%$ juice and high fat and fried V (HFV) (e.g., French fries). Implementation intentions were created for $\mathrm{FV}$ goals only.

\section{Measurement}

Parents and children received an email with a link to a secure, password protected website hosting the questionnaires when it was time for data collection. Parents and children completed separate online questionnaires. Parents provided demographic data at baseline and selfreported newsletter and website usage at post 1 . Process evaluation data were collected via logs maintained by study staff, and automatically within the game as children navigated it (e.g., logon rate, responses to questions embedded in the game).

The primary dependent variable was child FV intake. Because preferences for $F$ and $V$ vary [29], secondary analyses assessed $\mathrm{F}$ and $\mathrm{V}$ intake separately to provide a more detailed view of intervention effects on FV intake. At each data collection period, food and beverage intakes were measured via 3 unannounced 24 hour dietary recalls ( 2 weekday, 1 weekend day) conducted over the phone by trained staff using the Nutrient Data System for Research (NDSR-2009, Nutrition Coordinating Center, University of Minnesota, Minneapolis, MN) [52]. The dietary data collection team was blinded to group assignment. Servings of F and regular V (i.e., non-fat, non-fried) were calculated using the NDSR output. Three days of F and $\mathrm{V}$ intake at each data collection period were averaged to improve estimates of dietary intake. A conservative definition of FV intake was used in the analyses, which included F, excluding 100\% juice, and V, excluding HFV. The analyses examined only these variables because the intervention attempted to increase $\mathrm{F}$ and regular $\mathrm{V}$ intake, but not $100 \%$ juice, and HFV.

\section{Statistical analysis}

All statistical analyses were conducted using the Statistical Analysis Software (SAS) (version 9.3, SAS Institute Inc., Cary, NC, 2010). The statistician was not blinded to condition since the analyses required that the data be analyzed by group. Numerical (Skewness, Kurtosis, and Kolmogorov-Smirnov D) and graphical methods tested for data normality or any suspected outlier. Because the data were skewed and not normally distributed, the outcome variables were log-transformed for the analyses. Estimates (i.e. adjusted means) presented in the tables were back-transformed to the original scale.

Baseline demographic characteristics and FV intake were examined to identify group differences using chisquare analysis and analysis of variance (ANOVA) for categorical and continuous variables, respectively. 
All analyses were conducted only with children who had three dietary recalls at all three data collection periods (i.e., complete data). Intent-to-treat analyses assessed the influence of drop-outs on intervention effects.

A four-level between-group factor and a two-level within factor (post 1 and post 2) repeated measures analyses of covariance (RM ANCOVA) using mixed-effect models (Proc Mixed procedure in SAS) adjusted for baseline outcome values and selected covariates (e.g., child's gender, race/ethnicity, total energy intake, parent's age, and household education). The models evaluated change from baseline to post 1 or post 2 . Because multiple comparisons were conducted, there was a potential for type I error inflation. Therefore, the Bonferroni correction was applied, resulting in a significant $\mathrm{p}$-value of $<0.01$, which then was used for all analyses to determine statistical significance.

\section{Results}

\section{Baseline characteristics}

Four hundred parent/child pairs (were successfully recruited in approximately 8 months. Baseline characteristics of the study sample indicated children were almost evenly distributed by gender (female, 52.7\%) and were of diverse ethnicity (White-36.8\%, Hispanic 27.4\%, African American 26.4\%). Parents were mostly female (96.3\%), White (40.3\%), married (77.5\%), and 40-59 years old (55.3\%). Highest level of household education was predominately post-graduate study (36.7\%), and average household income was $>\$ 61,000$ (57.6\%) (Table 1).

Of the 400 children randomized to condition, 98\% had complete data at post $1(\mathrm{n}=392)$ and $97 \%$ at post 2 $(\mathrm{n}=387)$. Analyses were conducted with children who had complete data at post $2(\mathrm{n}=387)$ (Figure 1). There were no group differences in baseline demographic characteristics (e.g., child gender or ethnicity/race, parent age, ethnicity/race, education level) or FV intake (data not shown). There were also no statistically significant differences in demographic characteristics between children included in the analyses $(n=387)$ and those excluded $(\mathrm{n}=13)$ (data not shown).

\section{FV intake}

At baseline, children consumed an average of 1.8 daily servings of FV, excluding $100 \%$ juice and HFV. FV servings were comprised of a mean of 0.5 servings of $F$ and 1.2 servings of regular $\mathrm{V}$ (Table 2 ).

There was a significant group by time interaction for FV intake $\left(\mathrm{F}_{(6,777)}=3.24\right.$, $\mathrm{p}$-value $\left.<0.001\right)$. At post 1 , the Action $(\mathrm{p}<0.0001)$, and Coping $(\mathrm{p}<0.001)$ groups had significant increases in FV intake compared to baseline. However, at post 2, only the Action group maintained these increases $(\mathrm{p}<0.0001)$. The Action group had an almost $50 \%$ increase in FV intake at post 1 ( 0.72 servings), and maintained this increase at follow-up (0.68 servings) (Table 2).

A statistically significant time main effect was observed for $F$ intake $\left(F_{(2,780)}=28.61, p\right.$-value $\left.<0.0001\right)$. Regardless of group, compared to baseline, $\mathrm{F}$ intake increased at both post $1(\mathrm{p}<0.001)$ and post $2(\mathrm{p}<0.01)$. No significant interaction or main effects were observed for V (Table 2).

\section{Program participation}

Child participation rate was high: $91 \%$ of children played all 10 episodes of the videogame. Game-play rates did not vary by group $(\mathrm{p}=.813$, data not shown). Parents' participation rates varied, however: $33 \%$ reported reading 1-3 newsletters; $35 \%$ reported reading 4-6 newsletters; and $28 \%$ reported reading more than 6 newsletters. Parent self-reported website visitation rates were also highly variable: $55 \%$ reported visiting the parent website 1-5 times; $32 \%$ 6-10 times; and $28 \% 11$ or more times. Most (94.8\%) thought the videogame helped their child eat more FV. When asked to grade the overall program (videogame, newsletters, parent website), most parents gave it an A or B (92.0\%) (data not shown).

\section{Discussion}

This study examined longitudinal changes in FV intake after children played a 10 episode theoretically grounded serious videogame that systematically varied implementation intentions. The children who created Action plans as part of goal setting had significantly greater increases in short- and longer-term FV intake.

At baseline, FV intake was substantially below recommended levels for 9-13 year olds [10]. Low FV consumption among children is not surprising and has been observed by others. Fewer than $4 \%$ of $9-13$ year olds in the US reported consuming 7 or more servings of FV a day in 2006 , while $<20 \%$ consumed at least 5 servings a day [53].

Children in the Action group increased FV intake by .72 servings a day immediately after the intervention. This is somewhat higher than that reported in a review of FV studies with youth and adults which found an average intervention effect of .6 servings a day [13]; it also exceeds effects reported in a recent review and meta-analysis of school-based interventions with children which reported an increase of 0.25 portions a day, excluding juice [54]. The increase at post 1 assessment was less than that observed in the original SQ! game (1.0 servings) [18]. However, the original game included $100 \%$ juice and high fat $\mathrm{FV}$ when calculating the primary outcome [18]. When examining increases in FV only (.76 servings), immediate post-intervention effects were closer to those observed in the Action group in the current study (.72 servings) [18]. 
Table 1 Frequencies (n) and percentages (\%) of baseline demographic characteristics for the study sample, stratified by intervention group

\begin{tabular}{|c|c|c|c|c|c|}
\hline & $\begin{array}{l}\text { Total } \\
\text { n (\%) }\end{array}$ & $\begin{array}{l}\text { CONTROL } \\
\text { n ( \%) }\end{array}$ & $\begin{array}{l}\text { ACTION } \\
\text { n ( \%) }\end{array}$ & $\begin{array}{l}\text { COPING } \\
n(\%)\end{array}$ & $\begin{array}{l}\text { ВОтH } \\
\text { n (\%) }\end{array}$ \\
\hline Sample & $387(100.00)$ & $97(25.06)$ & $98(25.03)$ & $95(24.55)$ & $97(25.06)$ \\
\hline \multicolumn{6}{|l|}{ Child gender } \\
\hline Male & $183(47.29)$ & $45(24.59)$ & $48(26.23)$ & $43(23.50)$ & $47(25.68)$ \\
\hline Female & $204(52.71)$ & $52(25.49)$ & $50(24.51)$ & $52(25.49)$ & $50(24.51)$ \\
\hline \multicolumn{6}{|l|}{ Child race/ethnicity } \\
\hline Hispanic & 106 ( 27.39$)$ & $28(26.42)$ & $27(25.47)$ & $26(24.53)$ & $25(23.58)$ \\
\hline African American & $102(26.36)$ & $23(22.55)$ & $32(31.37)$ & $25(24.51)$ & $22(21.57)$ \\
\hline White & 141 ( 36.43 ) & $33(23.40)$ & $29(20.57)$ & $37(26.24)$ & $42(29.79)$ \\
\hline Other & $38(9.82)$ & $13(34.21)$ & $10(26.32)$ & $7(18.42)$ & $8(21.05)$ \\
\hline \multicolumn{6}{|l|}{ Parent gender } \\
\hline Male & $15(3.75)$ & $3(20.00)$ & $3(20.00)$ & $5(33.33)$ & $4(26.67)$ \\
\hline Female & 385 ( 96.25$)$ & 97 ( 25.19$)$ & $97(25.19)$ & $95(24.68)$ & $96(24.94)$ \\
\hline \multicolumn{6}{|l|}{ Parent race/ethnicity } \\
\hline Hispanic & $102(26.36)$ & $28(27.45)$ & $24(23.53)$ & $25(24.51)$ & $25(24.51)$ \\
\hline African American & $102(26.36)$ & $22(21.57)$ & $33(32.35)$ & $25(24.51)$ & $22(21.57)$ \\
\hline White & $156(40.31)$ & $35(22.44)$ & $36(23.08)$ & $40(25.64)$ & $45(28.85)$ \\
\hline Other & $27(6.98)$ & $12(44.44)$ & $5(18.52)$ & $5(18.52)$ & $5(18.52)$ \\
\hline \multicolumn{6}{|c|}{ Highest household education } \\
\hline Some College/Tech or Less & $124(32.04)$ & $31(25.00)$ & $38(30.65)$ & $29(23.39)$ & $26(20.97)$ \\
\hline College Graduate & $121(31.27)$ & $26(21.49)$ & $26(21.49)$ & $30(24.79)$ & $39(32.23)$ \\
\hline Post Graduate study & $142(36.69)$ & $40(28.17)$ & $34(23.94)$ & $36(25.35)$ & $32(22.54)$ \\
\hline \multicolumn{6}{|c|}{ Average annual household income } \\
\hline$\leq \$ 61,000$ & $164(42.38)$ & $43(26.22)$ & $44(26.83)$ & $45(27.44)$ & $32(19.51)$ \\
\hline$>\$ 61,000$ & $223(57.62)$ & $54(24.22)$ & $54(24.22)$ & $50(22.42)$ & $65(29.15)$ \\
\hline \multicolumn{6}{|l|}{ Parent age } \\
\hline 20-39 & $173(44.70)$ & $46(26.59)$ & $46(26.59)$ & $40(23.12)$ & $41(23.70)$ \\
\hline $40-59$ & $214(55.30)$ & $51(23.83)$ & $52(24.30)$ & $55(25.70)$ & $56(26.17)$ \\
\hline \multicolumn{6}{|l|}{ Parent marital status } \\
\hline Married & $300(77.52)$ & $81(27.00)$ & $73(24.33)$ & $70(23.33)$ & $76(25.33)$ \\
\hline Not Married & $87(22.48)$ & $16(18.39)$ & $25(28.74)$ & $25(28.74)$ & $21(24.14)$ \\
\hline
\end{tabular}

There were also differences in dietary assessment methods and procedures. Although both used 24 hour dietary recalls, the original SQ! used an online dietary recall system that only quantified F, 100\% juice, regular $\mathrm{V}$, and high fat $\mathrm{V}$ intakes; the original SQ! game also collected 4 recalls on non-consecutive week days, while SQ2 collected recalls on 3 days, consisting of 2 week days and one weekend day.

Although FV intake was still below recommended levels [10], the increase observed in the Action group was nearly $50 \%$ above baseline, which is worth noting. To encourage personal mastery [15] (i.e., goal attainment) via selfefficacy, the intervention gradually increased goal intensity rather than starting with a likely more difficult FV goal of at least 5 servings of FV a day [37]. It is possible that a more intensive intervention approach would have resulted in greater increases in FV intake. Future research is needed to investigate this.

Maintenance of intervention effects on FV intake is an important public health issue [12], but mixed effects have been observed [12,13]. Knai et al. [12] examined studies conducted only with youth that had a follow up period of at least 3 months. They found intervention effects ranging from increases of .3 to .99 servings a day. The present study is consistent with those findings. In the current study, the Action group maintained an 


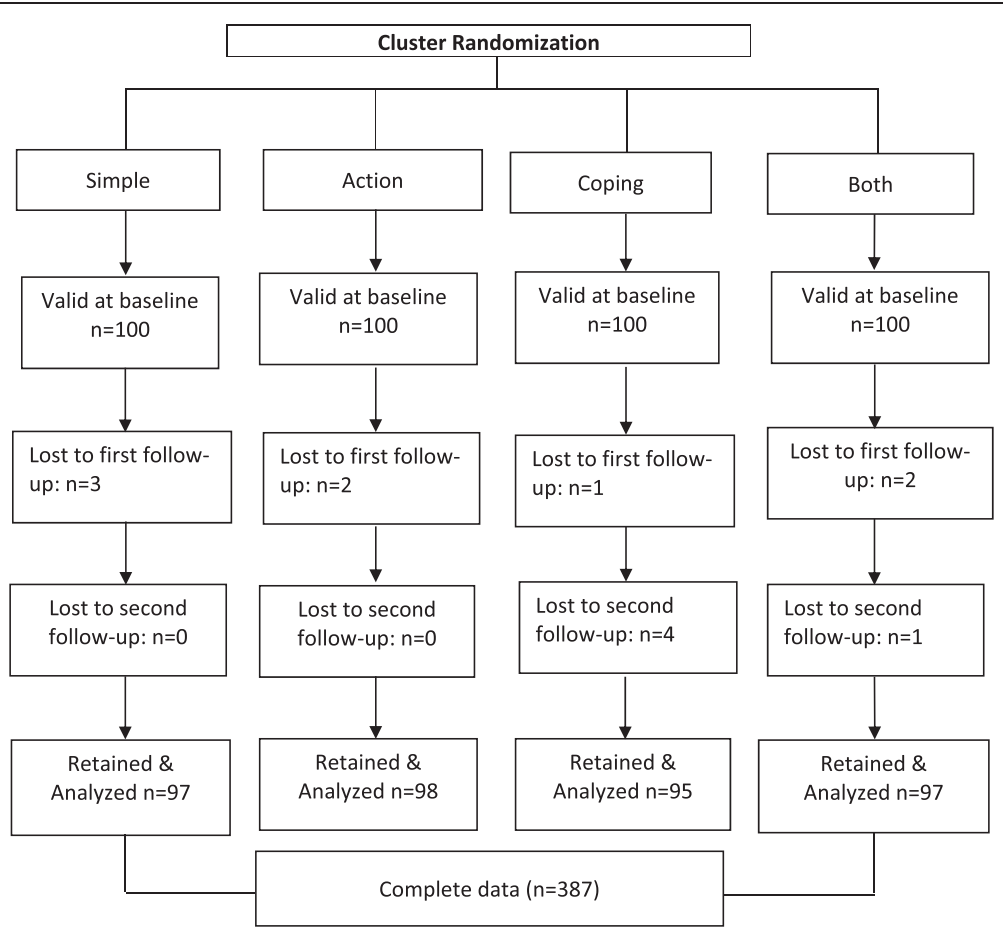

Figure 1 Consort diagram of the randomization and inclusion process.

increase of 0.68 servings FV for 3 months after completion of the intervention, representing a $41 \%$ increase over baseline intake. This provides initial evidence that dietary interventions to increase child FV intake longterm would benefit from including Action plans as part of goal setting. A possible explanation of the mechanism through which Action plans might work is that children are not experienced at setting goals to eat more FV [55] and need guidance on how to accomplish this task. Therefore, creating specific plans of how to achieve their FV goals was likely beneficial in that it provided guidance in this area. This is consistent with implementation intention theory [30]. Another possible explanation is that the goals gradually increased in difficulty, and FV options offered during goal setting were tailored to the child's FV preferences. This may have increased the likelihood the child would strive to meet the goal, particularly when the goal was coupled with a specific plan of how it would be attained. This likely contributed to personal mastery, which is the most effective technique for achieving behavior change [15]. Finally, according to Rothman, satisfaction with behavior change is associated with behavioral maintenance in adults [47]. Satisfaction is a reflection of whether the effort that went into obtaining the goal was "worth it". It could be that the children who created Action plans perceived meeting goals as easier than children in the other groups (i.e., required less effort) because they had a specific plan of how to accomplish the FV goal, thus making them more satisfied with the outcome. Research is needed to investigate this possibility.

It is somewhat surprising that the group that created both Action and Coping plans did not increase and maintain their FV intake or that the changes were not equal to or similar to those seen in the Action group alone. One possible explanation is that the cognitive effort required to create two types of implementation intentions was too great for children this age. Other possible explanations are that creating both types of plans resulted in a dilution effect or that children this age are not developmentally ready to create and follow two types of plans for one goal. Additional research is needed to investigate these possibilities.

Regardless of group, children increased F consumption at both post 1 and post 2 . No treatment effects were observed for V. Although the intervention was not designed to provide a clear explanation for this, it is well established that children prefer F over V $[29,56]$, which may offer a partial explanation. Further, the intervention was powered to detect a small effect of 0.51 serving increase in FV. Increases observed in F and V separately were smaller than this. It is worth noting, however, that the Action group increased and maintained $\mathrm{F}$ intake more than $70 \%$ over baseline and V intake by nearly $30 \%$. This was not observed in the other groups. Although these increases did not reach the level of statistical 


\begin{tabular}{|c|c|c|c|c|c|}
\hline & \multirow{2}{*}{$\begin{array}{l}\text { Baseline } \\
M(S E)\end{array}$} & \multirow{2}{*}{$\begin{array}{l}\text { Post \#1 } \\
M(S E)\end{array}$} & \multirow{2}{*}{$\begin{array}{l}\text { Post \#2 } \\
M(S E)\end{array}$} & \multicolumn{2}{|l|}{ Change $^{2}$} \\
\hline & & & & Post \#1 & Post \#2 \\
\hline \multicolumn{6}{|c|}{ Fruit \& vegetable ${ }^{g t * *}$} \\
\hline Control & $1.86(0.04)$ & $2.20(0.04)$ & $1.89(0.04)$ & 0.35 & 0.04 \\
\hline Action & $1.64(0.04)$ & $2.37(0.04)$ & $2.32(0.04)$ & $0.72^{* * *}$ & $0.68^{* * *}$ \\
\hline Coping & $1.83(0.04)$ & $2.31(0.04)$ & $2.11(0.05)$ & $0.48^{* *}$ & 0.28 \\
\hline Both A \& C & $2.11(0.04)$ & $2.28(0.04)$ & $2.05(0.04)$ & 0.17 & -0.06 \\
\hline Total & $1.84(0.03)$ & $2.27(0.03)$ & $2.07(0.03)$ & 0.43 & 0.23 \\
\hline \multicolumn{6}{|l|}{ Fruit } \\
\hline Control & $0.61(0.04)$ & $0.84(0.04)$ & $0.60(0.04)$ & 0.23 & -0.01 \\
\hline Action & $0.46(0.04)$ & $0.82(0.04)$ & $0.79(0.04)$ & 0.35 & 0.33 \\
\hline Coping & $0.54(0.04)$ & $0.84(0.04)$ & $0.67(0.04)$ & 0.29 & 0.13 \\
\hline Both A\&C & $0.60(0.04)$ & $0.90(0.04)$ & $0.69(0.04)$ & 0.29 & 0.09 \\
\hline Total ${ }^{* * *}$ & $0.54(0.03)$ & $0.82(0.03)$ & $0.67(0.03)$ & $0.32^{* *}$ & $0.23^{*}$ \\
\hline \multicolumn{6}{|c|}{ Regular Vegetables } \\
\hline Control & $1.18(0.04)$ & $1.26(0.04)$ & $1.26(0.04)$ & 0.08 & 0.07 \\
\hline Action & $1.15(0.04)$ & $1.47(0.04)$ & $1.48(0.04)$ & 0.32 & 0.33 \\
\hline Coping & $1.24(0.04)$ & $1.37(0.04)$ & $1.38(0.04)$ & 0.13 & 0.14 \\
\hline Both A \& C & $1.45(0.04)$ & $1.34(0.04)$ & $1.32(0.04)$ & -0.10 & -0.13 \\
\hline Total & $1.24(0.03)$ & $1.36(0.03)$ & $1.35(0.03)$ & 0.12 & 0.11 \\
\hline
\end{tabular}

Abbreviations: $\mathrm{M}(\mathrm{SE})$ = adjusted mean ( standard error), " $\mathrm{g}$ " = group; " $\mathrm{t}$ " = time " $\mathrm{gt}^{\prime}=$ the interaction of group by time, "ANCOVA" = Analysis of Covariance. 1: Repeated measures ANCOVA was adjusted for gender, race/ethnic group, total energy intake, and parent's age, education level; adjusted means presented here were back-transformed to original scale (servings). 2: Change from baseline.

Significance level at ${ }^{*} p<0.01,{ }^{* *} p<0.001,{ }^{* * *} p<0.0001$.

significance, the percentage of increase for each is fairly large. Increases of this magnitude are of practical significance and should be investigated in future research.

The majority of children (91\%) played all 10 episodes of the videogame. The number of episodes played represents program dose, or the amount of intervention content to which the participants were exposed [57]. Game-play rates did not vary by group, meaning that children in all intervention arms received a comparable program dose. This is higher than that observed in the original game, in which $73.6 \%$ of children played all $10 \mathrm{ep}-$ isodes [18]. This could partially be explained by the differences in setting. SQ was played on computers in the school environment following a pre-set schedule, while SQ2 was played online following a schedule determined by the child or parent. This additional flexibility may have increased participation. It could also be partially explained by the high involvement of children in the development of SQ2, which helped ensure the storyline, characters, and game-play features were appealing, that the behavioral components were understood by children, and that technical issues that could impact game-play were identified and addressed prior to the outcome evaluation $[37,58]$.

Although the parents reported they believed the program was beneficial for their child, they did not report high levels of participation in the parent intervention. The low participation rates in the parent intervention were disappointing, but not surprising. Low parent participation rates have been observed in online childfocused programs [19]. Parents are gatekeepers of the home environment [59]; therefore, it is important to identify effective ways to more fully engage parents in online programs attempting to change child behavior.

Strengths of this study include a strong measure of dietary intake; excluding 100\% juice and HFV from the primary analyses; a sample powered to detect meaningful change; high participation by children; low attrition rates; a large, multi-ethnic sample; and an intervention that was designed within a multi-theoretical framework with input from the target population. Weaknesses include no group that did not set a goal; age of the children, which may have influenced the accuracy of the dietary recalls; the relatively high income and education levels of the families who participated in the study; and conducting the study in only one geographic region, which makes it difficult to generalize results to other areas. Finally, the intervention utilized a multi-theoretical approach. While this was a strength of the study, it could have potentially diluted the impact or focus of the intervention.

\section{Conclusions}

Serious video games that include complex behavioural procedures appear to be an effective method for increasing FV intake in children. Action intentions were effective at helping children increase and maintain FV intake. Behavior change programs should consider including action plans as part of goal setting to increase both short and longer-term intervention effectiveness.

\section{Future directions}

Future research should include a more detailed analysis of the associations between FV consumption and goal attainment; associations among parent behaviors, the home environment, and child behaviors, including FV intake; and the effect of greater parent involvement on child FV consumption. Even though the socioeconomic level of families participating in this study was fairly high, child FV intake was low. Future research needs to investigate the possible reasons for this.

\section{Abbreviations}

ANOVA: Analysis of Variance; ARS: Agricultural Research Service; e.g.: For example; F: Fruit; FV: Fruit and vegetable; HD: National Institutes of Health, National Institute of Child Health \& Human Development; HFV: High fat 
vegetables; i.e.: In other words; n: Frequency; NDSR: Nutrient Data System for Research; RM ANCOVA: Repeat Measures Analysis of Covariance; SAS: Statistical Analysis Software; SQ!! Squire's Quest!; SQ2: Squire's Quest! II: Saving the Kingdom of Fivealot; USDA: United States Department of Agriculture; V: Vegetable; \%: Percent/percentage.

\section{Competing interests}

The authors declare that they have no competing interests.

\section{Authors' contributions}

DT was principal investigator and conceptualized the study; RBhatt was the project manager and coordinated all aspects of the study; IV oversaw the dietary data collection; JB, KC, and TB contributed to the conceptual design of the study and participated in interpretation of the data; TB was also principal investigator for the original study; $Y L$ was biostatistician for the current study, conducted the analyses, and participated in data interpretation. All authors read and approved the final manuscript.

\section{Acknowledgements}

This work is a publication of the United States Department of Agriculture/ Agricultural Research Center (USDA/ARS), Children's Nutrition Research Center, Department of Pediatrics, Baylor College of Medicine, Houston, Texas. This project was supported by the National Institutes of Health, National Institute of Child Health \& Human Development grant \#HD050595 (to Dr. Thompson). This work is also a publication of the USDA/ARS, Children's Nutrition Research Center, Department of Pediatrics, Baylor College of Medicine, Houston, Texas, and funded in part with federal funds from the USDA/ARS under Cooperative Agreement No. 58-6250-0-008. The contents of this publication do not necessarily reflect the views or policies of the USDA, nor does mention of trade names, commercial products, or organizations imply endorsement from the U.S. government. We would like to thank the children and parents who participated in this research, and the SQ2 data collection and intervention staffs. We would also like to extend our thanks to Archimage, Inc. of Houston, TX for its game design services.

\section{Author details}

'USDA/ARS Children's Nutrition Research Center, Baylor College of Medicine, 1100 Bates Street, Houston, TX, USA. 'Department of Family and Community Medicine, Baylor College of Medicine, 3701 Kirby Drive, Houston, TX, USA.

\section{Received: 13 August 2014 Accepted: 6 March 2015}

Published online: 18 March 2015

\section{References}

1. US Department of Health and Human Services. Healthy People 2020: Understanding and Improving Health. 2nd ed. Washington, DC: Government Printing Office; 2011.

2. Bazzano LA. The high cost of not consuming fruits and vegetables. J Am Diet Assoc. 2006;106:1364-8.

3. Boeing H, Bechthold A, Bub A, Ellinger S, Haller D, Kroke A, et al. Critical review: Vegetables and fruit in the prevention of chronic diseases. Eur J Nutr. 2012;51:637-63.

4. Ledikwe JH, Blanck HM, Kettel Khan L, Serdula MK, Seymour JD, Tohill BC, et al. Dietary energy density is associated with energy intake and weight status in US adults. Am J Clin Nutr. 2006;83:1362-8.

5. Ledoux TA, Hingle MD, Baranowski T. Relationship of fruit and vegetable intake with adiposity: A systematic review. Obes Rev. 2011:12:e143-50.

6. Kudlova E, Schneidrova D. Dietary patterns and their changes in early childhood. Cent Eur J Public Health. 2012;20:126-34.

7. Mikkila V, Rasanen L, Raitakari OT, Pietinen P, Viikari J. Consistent dietary patterns identified from childhood to adulthood: The Cardiovascular Risk in Young Finns Study. Br J Nutr. 2005;93:923-31.

8. Lien N, Lytle LA, Klepp KI. Stability in consumption of fruit, vegetables, and sugary foods in a cohort from age 14 to age 21. Prev Med. 2001;33:217-26.

9. te Velde SJ, Twisk JW, Brug J. Tracking of fruit and vegetable consumption from adolescence into adulthood and its longitudinal association with overweight. Br J Nutr. 2007;98:431-8.

10. U.S. Department of Agriculture, U.S. Department of Health and Human Services. Dietary Guidelines for Americans, 2010 - 7th Edition. Washington, DC: U.S. Government Printing Office; 2010. http://www.health.gov/dietaryguidelines/ dga2010/DietaryGuidelines2010.pdf.
11. Krebs-Smith SM, Guenther PM, Subar AF, Kirkpatrick SI, Dodd KW. Americans do not meet federal dietary recommendations. J Nutr. 2010;140:1832-8.

12. Knai C, Pomerleau J, Lock K, McKee M. Getting children to eat more fruit and vegetables: A systematic review. Prev Med. 2006;42:85-95.

13. Ammerman AS, Lindquist $\mathrm{CH}$, Lohr KN, Hersey J. The efficacy of behavioral interventions to modify dietary fat and fruit and vegetable intake: A review of the evidence. Prev Med. 2002;35:25-41.

14. Baranowski T, Anderson C, Carmack C. Mediating variable framework in physical activity interventions. How are we doing? How might we do better? Am J Prev Med. 1998;15:266-97.

15. Bandura A. Social Foundations of Thought and Action: A Social Cognitive Theory. Englewood Cliffs, NJ: Prentice Hall; 1986.

16. Cullen KW, Baranowski T, Smith SP. Using goal setting as a strategy for dietary behavior change. J Am Diet Assoc. 2001;101:562-6.

17. Michie S, Abraham C, Whittington C, McAteer J, Gupta S. Effective techniques in healthy eating and physical activity interventions: A metaregression. Health Psychol. 2009;28:690-701.

18. Baranowski T, Baranowski J, Cullen KW, Marsh T, Islam N, Zakeri I, et al. Squire's Quest! Dietary outcome evaluation of a multimedia game. Am J Prev Med. 2003;24:52-61.

19. Baranowski T, Baranowski JC, Cullen KW, Thompson DI, Nicklas T, Zakeri IF, et al. The Fun, Food, and Fitness Project (FFFP): The Baylor GEMS pilot study. Ethn Dis. 2003;13:S30-9.

20. Thompson D, Baranowski J, Cullen K, Baranowski T. Development of a theorybased internet program promoting maintenance of diet and physical activity change to 8-year-old African American girls. Comput Educ. 2007;48:446-59.

21. Thompson D, Baranowski T, Buday R, Baranowski J, Juliano M, Frazior M, et al. In pursuit of change: Youth response to intensive goal setting embedded in a serious videogame. J Diabetes Sci Technol. 2007;1:907-17.

22. Thompson D, Baranowski T, Baranowski J, Cullen K, Jago R, Watson K, et al. Boy Scout 5-a-Day Badge: Outcome results of a troop and Internet intervention. Prev Med. 2009:49:518-26.

23. Cullen KW, Thompson D, Boushey C, Konzelmann K, Chen TA. Evaluation of a web-based program promoting healthy eating and physical activity for adolescents: Teen Choice: Food and Fitness. Health Educ Res. 2013;28:704-14.

24. Thompson D, Mahabir R, Bhatt R, Boutte C, Cantu D, Vazquez I, et al. Butterfly Girls; promoting healthy diet and physical activity to young African American girls online: Rationale and design. BMC Public Health. 2013;13:709.

25. Cullen KW, Watson KB, Zakeri I, Baranowski T, Baranowski JH. Achieving fruit, juice, and vegetable recipe preparation goals influences consumption by 4th grade students. Int J Behav Nutr Phys Act. 2007;4:28.

26. Latif $H$, Watson $\mathrm{K}$, Nguyen $\mathrm{N}$, Thompson D, Baranowski J, Jago R, et al. Effects of goal setting on dietary and physical activity changes in the Boy Scout badge projects. Health Educ Behav. 2011;38:521-9.

27. Simons M, Baranowski J, Thompson D, Buday R, Abdelsamad D, Baranowski T. Child goal setting of dietary and physical activity in a serious videogame. Games Health J. 2013;2:150-7.

28. Shilts MK, Horowitz M, Townsend MS. Goal setting as a strategy for dietary and physical activity behavior change: A review of the literature. Am J Health Promot. 2004;19:81-93.

29. Domel SB, Baranowski T, Davis H, Leonard SB, Riley P, Baranowski J. Measuring fruit and vegetable preferences among 4 th- and 5 th-grade students. Prev Med. 1993;22:866-79.

30. Gollwitzer PM. Implementation intentions: Strong effects of simple plans. Am Psychol. 1999;54:493-503.

31. Gollwitzer PM, Sheeran P. Implementation intentions and goal achievement: a meta-analysis of effects and processes. Adv Exp Soc Psychol. 2006;38:69-119.

32. Bargh JA, Gollwitzer PM, Lee-Chai A, Barndollar K, Trotschel R. The automated will: Nonconscious activation and pursuit of behavioral goals. J Pers Soc Psychol. 2001;81:1014-27.

33. Lytle LA, Varnell S, Murray DM, Story M, Perry C, Birnbaum AS, et al. Predicting adolescents' intake of fruits and vegetables. J Nutr Educ Behav. 2003;35:170-5.

34. Frauenknecht M. The Social Problem-Solving Inventory for Adolescents (SPSI-A): A Manual for Application, Interpretation, and Psychometric Evaluation. Morgantown, WV: PNG Publications; 2003.

35. Thompson D, Bhatt R, Watson K. Physical activity problem-solving inventory for adolescents: Development and initial validation. Pediatr Exerc Sci. 2013;25:448-67.

36. Thompson D, Baranowski T, Buday R, Baranowski J, Thompson V, Jago R, et al. Serious video games for health: How behavioral science guided the development of a serious video game. Simul Gaming. 2010;41:587-606. 
37. Thompson D, Bhatt R, Lazarus M, Cullen K, Baranowski J, Baranowski T. A serious video game to increase fruit and vegetable consumption among elementary aged youth (Squire's Quest! II): Rationale, design, and methods. JMIR Res Protoc. 2012;1:e19.

38. Gallo IS, Gollwitzer PM. Implementation intentions: A look back at fifteen years of progress. Psicothema. 2007;19:37-42.

39. Gratton L, Povey R, Clark-Carter D. Promoting children's fruit and vegetable consumption: interventions using the Theory of Planned Behaviour as a framework. Br J Health Psychol. 2007;12:639-50.

40. Rideout VJ, Foehr UG, Roberts DF. Generation M2: Media in the lives of 8- to 18-year-olds. Menlo Park, CA: Kaiser Family Foundation; 2010. http://files.eric. ed.gov/fulltext/ED527859.pdf.

41. Männikkö N, Mendes L, Barbosa F, Reis LP. Health determinants related to digital game playing: A systematic review. J Health Sci. 2014;4:53-63.

42. Baranowski T, Buday R, Thompson DI, Baranowski J. Playing for real: Video games and stories for health-related behavior change. Am J Prev Med. 2008:34:74-82.

43. Baranowski T, Baranowski J, Thompson D, Buday R, Jago R, Griffith MJ, et al. Video game play, child diet, and physical activity behavior change: A randomized clinical trial. Am J Prev Med. 2011;40:33-8.

44. Thompson D. What serious video games can offer child obesity prevention. JMIR Serious Games. 2014;2:e8.

45. Ryan RM, Deci EL. Self-determination theory and the facilitation of intrinsic motivation, social development, and well being. Am Psychol. 2000;55:68-78.

46. McGuire WJ. Resistance to persuasion conferred by active and passive prior refutation of the same and alternative counterarguments. J Abnorm Soc Psychol. 1961;63:326-32.

47. Rothman AJ. Toward a theory-based analysis of behavioral maintenance. Health Psychol. 2000;19:64-9.

48. Petty RE, Cacioppo JT. Communication and Persuasion: Central and Peripheral Routes to Attitude Change. New York: Springer; 1986.

49. Schunk DH. Vicarious influences on self-efficacy for cognitive skill learning. J Soc Clin Psychol. 1986:4:316-27.

50. Green MC, Brock TC. The role of transportation in the persuasiveness of public narratives. J Pers Soc Psychol. 2000;79:701-21.

51. Lu AS, Thompson D, Baranowski J, Buday R, Baranowski T. Story immersion in a health videogame for childhood obesity prevention. Games Health J. 2012;1:37-44.

52. Lytle LA, Murray DM, Perry CL, Eldridge AL. Validating fourth-grade students' self-report of dietary intake: Results from the 5 A Day Power Plus program. J Am Diet Assoc. 1998;98:570-2.

53. Guenther PM, Dodd KW, Reedy J, Krebs-Smith SM. Most Americans eat much less than recommended amounts of fruits and vegetables. J Am Diet Assoc. 2006;106:1371-9.

54. Evans CE, Christian MS, Cleghorn CL, Greenwood DC, Cade JE. Systematic review and meta-analysis of school-based interventions to improve daily fruit and vegetable intake in children aged 5 to $12 \mathrm{y}$. Am J Clin Nutr. 2012;96:889-901

55. Cullen KW, Baranowski T, Baranowski J, Warnecke C, de Moor C, Nwachokor A, et al. "5 A Day" achievement badge for urban Boy Scouts: Formative evaluation results. J Cancer Educ. 1998;13:162-8.

56. Perry CL, Bishop DB, Taylor GL, Davis M, Story M, Gray C, et al. A randomized school trial of environmental strategies to encourage fruit and vegetable consumption among children. Health Educ Behav. 2004;31:65-76.

57. Linnan L, Steckler A. Process evaluation for public health interventions and research: An overview. In: Linnan L, Steckler A, editors. Process Evaluation for Public Health Interventions and Research. San Francisco: Jossey-Bass; 2002. p. 1-23.

58. Thompson D. Talk to me, please! The importance of qualitative research to games for health. Games Health J. 2014;3:117-8.

59. Gruber KJ, Haldeman LA. Using the family to combat childhood and adult obesity. Prev Chronic Dis. 2009;6:A106.

\section{Submit your next manuscript to BioMed Central and take full advantage of:}

- Convenient online submission

- Thorough peer review

- No space constraints or color figure charges

- Immediate publication on acceptance

- Inclusion in PubMed, CAS, Scopus and Google Scholar

- Research which is freely available for redistribution

Submit your manuscript at www.biomedcentral.com/submit 